\title{
Avrupa Birliği Ülkelerinin Boşanma Oranı Analizi
}

\section{Ersin $\operatorname{KIRAL}^{1}$}

ÖZ: Bu makale Markov zincir modelini kullanarak kaba boşanma oranların tahmin etmektedir. Markov modelleri 27 Avrupa Birliği ülkesinin boşanma oranları için oluşturulmuştur. Boşanma oranları, başlangıç olasıllı matrisi ve geçiş olasıllğ matrisinin çarpımı ile tahmin edilmiştir. Tahminlerin limit matrisleri bulunmuştur. Bu çalışmanın temel sonuçları şunlardır: i) 2015 yılı itibarıyla üst kategoride gerçekleşen boşanma oranlarının uzun vadede aynı kategoridedir. ii) Sadece Belçika'nın kaba boşanma hizl, mutlaka AB 2015 ortalamasının üzerinde gerçekleşecek ve durağan kalacaktır. iii) Üç ve dört kategoriye sahip Markov modellerine dayanılarak, 2018 boşanma oranları büyük olasılıkla daha düşük kategorilerde gerçekleşecek ve durağan hale gelecektir, iv) Türkiye'nin ham kaba boşanma hızı uzun vadede kesinlikle AB 27'nin 2015 ortalamasinin altında kalacaktır ve v) Beş kategori ile oluşturulan Markov modellerine göre başlangıç boşanma olasılığı üst kategorilerde olan ülkelerin boşanma hızının üst kategorilerde ve başlangıç olasılığı alt kategorilerde olan ${ }^{2} \ddot{u l l k e l e r i n ~ b o s ̧ a n m a ~}$ hızının ise alt kategorilerde durağanlaşacaktır.

Anahtar Kelimeler: Boşanma Hızı, Geçiş Olasılıkları, Markov Analizi JEL Kodu: J12, C2, C6

\section{Analysis of the European Union Divorce Rates}

\begin{abstract}
This article estimates crude divorce rates using Markov chain model. Markov models are constructed for the divorce rates of 27 European Union countries. Divorce rates are estimated by the product of the initial probability matrix and transition probability matrix. Limiting matrices of the estimations are found. Main results of this study are i) divorce rates in higher categories in 2015 stay in the same categories in the long run, ii) Only Belgium's crude divorce rate will certainly be realized and be stationary over 2015 mean of EU 27, iii) Based on Markov models with three and four categories, 2018 divorce rates will more likely be realized and be stationary in lower categories, iv) Turkey's crude divorce rate will certainly be under 2015 mean of EU 27 in the long run, and v) Based on Markov model with five categories, the divorce rate of the countries with higher likelihood of divorce in the upper categories will be stationary in the upper categories and the divorce rate of the countries with lower likelihood of starting in the lower categories will be stationary in the lower categories.
\end{abstract}

Key words: Divorce Rates, Transition Probabilities, Markov Analysis JEL Codes: J12, C2, C6

\footnotetext{
${ }^{1}$ Yrd. Doç. Dr., Çukurova Üniversitesi, İktisadi ve İdari Bilimler Fakültesi, Ekonometri Bölümü, ekiral@cu.edu.tr, orcid.org/0000-0001-6040-1795
} 


\section{Giriș}

Kaba boşanma hızı (BH), boşanma sayılarının nüfus içerisindeki her 1000 kişiye oranıdır (Crosby, 1980). Boşanma, bazı Avrupa Birliği üye ülkelerde 50 yıl öncesine kadar yasal değildi. Yasal düzenlemeyle boşanma 48 yıl önce İtalya'da, 38 yıl önce İspanya'da, 22 yıl önce İrlanda'da ve yedi y1l önce Malta'da mümkün hale gelmiştir (Eurostat 2017).

Avrupa'da boşanmaya etki eden etmenler literatürde farklı boyutlarıyla tartışılmıştır. Hükümetin ve kilisenin boşanma politikaları, boşanmanın kültürel kabulü, çiftlerin farklı etnik kökenden olmaları, çiftlerin evlilik öncesi birlikte yaşamaları, boşanma maliyetinin yüksek olması, çocuk olması ve mal paylaşımı bunlardan bazılarıdır.

Avrupa'da genel olarak evlilik öncesi birlikte yaşama ile boşanma riski arasında pozitif bir ilişki vardır. Evlilik öncesi aynı evde yaşayan çiftlerin diğerlerine göre boşanma riski \%33 daha fazladır (Wagner ve Weiß, 2006). Ayrıca, kültürel olarak farklı etnik kökene sahip olan çiftlerin boşanma riski daha yüksektir (Smith, Maas ve Tubergen, 2012). Avrupa'da boşanmayı kolaylaştırıcı yasaların hayata geçirilmesi 1960-2002 döneminde boşanma oranını \%20 yükseltmiştir (González ve Viitanen, 2003). Karşılıksız ve tek taraflı boşanmanın hayata geçirilmesi ile boşanma oranı 0,6 artmıştır (González ve Viitanen, 2009). Boşanma oranları hükümetin din ve boşanma politikaları ile doğrudan ilişkilidir. İrlanda boşanma oranı bu nedenlerden dolayı en düşüktür. Meagher (2015)'e göre İrlanda'da çiftlerin boşanabilmeleri için dört yıl ayrı yaşamaları gerekmektedir. Ayrıca yasal ayrılma maliyeti 12,000-20,000 euro arasında değişmektedir. Avrupa Birliği üye ülkelerinden olan Polonya' da insanların \%90'dan fazlası dindar olduğunu ifade etmektedir. $\mathrm{Bu}$ ülkede kilise boşanmayı reddetmekte ancak ayrılma konusuna toleranslı yaklaşmaktadır. Boşanma sonrasında evlilik dışı birliktelik yaşayanların ayinlere katılması yasaklanmıştır. Bu durum dindar olan insanlar için caydırıcı bir önlem olarak görülmektedir. Mahkemeler ise öncelikle aile birliğinin devamını sağlayabilmek için boşanma davalarını ileri tarihlere ertelemektedir. Mahkemeler açısından bu durum Türkiye'de de farklı değildir.

$\mathrm{Bu}$ makalenin asıl amacı Markov modeli kullanarak 27 AB ülkesinin ve Türkiye'nin kaba boşanma hızlarını 2018 ve sonrası için hesaplamaktır.

Makalenin geriye kalan kısmı aşağıdaki şekilde düzenlenmiştir. Bir sonraki bölümde boşanma oranları ile ilgili literatür verilmiştir. Bölüm 3 'te bu çalışmanın veri ve yöntemi verilmiştir. Bölüm 4'te Markov yöntemiyle boşanma hızı tahminlenmiştir. Bölüm 5'te modelin istatistiksel anlamlılığ test edilmiştir. Bölüm 6'da çalışmanın bulguları verilmiştir ve Bölüm 7'de çalışma sonuçlandırılmıştır. 


\section{Literatür}

Kneip and Bauer (2009), geçtiğimiz on y1llar boyunca Avrupa'daki boşanma oranındaki artışa boşanma yasalarında çeşitli değişikliklerin eşlik ettiğini tartışmıştır. Yazarlar, Batı Avrupa ülkelerinde tek taraflı boşanma oranının hayata geçirilmesinin boşanma oranına etkisini incelemek için sabit etki regresyon modelleri kullanmış ve De fakto tek taraflı boşanma uygulamalarının boşanma oranının sürdürülebilir bir şekilde arttığını, ancak tek taraflı boşanma için yasal hakların uzun vadede etkisinin olmadığını bulmuşlardır. Yazarlar, tek taraflı boşanma yasasının genel olarak uygulanması boşanma oranını kalıcı olarak arttırdığını göstermiştir. Ancak anahtar bağımsız değişkenlerin dinamik etki modelinin, açık bir şekilde tek taraflı boşanma yasalarının sadece az ve kısa vadeli bir etkisi olduğunu göstermiştir.

González ve Viitanen (2009), Avrupa'da boşanmayı kolaylaştırıcı yasal reformların boşanma oranları üzerine etkisini analiz etmişlerdir. Yazarlar, ülkelerin boşanma yasalarındaki reformların doğasını ve farklı zamanlamasını kullanarak 54 yıldan oluşan panel veri oluşturmuştur. $\mathrm{Bu}$ reformlar yasal boşanma, tek taraflı boşanma ve karşılıksız boşanmayı kapsamaktadır. Karşılıksız ve tek taraflı boşanmanın hayata geçirilmesi ile boşanma oranında 0,6 artış hesaplanmıştır ki 2002 yılında boşanma hızının ortalama 2 olduğu düşünülürse bu oran büyük bir orandir.

Hiller ve Recoules (2013), boşanma oranlarındaki değişiklikler, boşanma yasaları ve boşanmanın kültürel kabulü arasındaki karşılıklı etkileşime odaklanmıştır. Yazarlar boşanmaya yönelik tutumların, kültürel aktarım mekanizmaları yoluyla geliştiği, tutucu bir dengenin, liberal bir denge ile birlikte var olabileceği, ekonomik şokların bir denge değişikliğine neden olabileceği ve geçiş süresince boşanma oranındaki artışların yasal değişikliklerden önce geldiği sonucuna ulaşmıştır.

Balestrino, Ciardi ve Mammini (2013), pek çok Batılı ekonomide, Refah Devletinin gelişmesinin ailenin rolünün düşüşüyle çakıştığını, boşanmanın pahalı bir süreç olduğunu ve olasılığının sınırlı rasyonel temsilciler tarafından aşırı tahmin edilebileceğini tartışmıştır. Dolayısıyla, yazarlara göre evlilik sayısının azalması ve beraber yaşamanın artmasının bir nedeni bu olabilir. Ayrıca yazarlar modelin tahminlerinin tam rasyonaliteye sahip standart bir modelden daha çok stilize edilmiş olgularla aynı çizgide olduğunu göstermiştir.

González-Val ve Marcén (2012), 1930-2006 periyodunda 16 Avrupa ülkesinde boşanma oranındaki kalıcı şokların sıklığını araştırmıştır. Yazarlar, yapısal bir kırılmanın özel bir olayla ilişkili olup olamadığını analiz etmiştir. Boşanma oranının durağan bir seri olup olmadığını, birim kök sergileyip sergilemediğini veya yapısal kırılmaya bağlı bir süreç etrafında durağan olup olmadığını incelemişler ve bütün şokların boşanma oranı üzerinde geçici etkiye sahip olmadığı sonucuna varmışlardır. Sonuçlar, kalıcı etkilere sahip olan nadiren 
yaşanan şokların durağanlığının yanı sıra, tüm şokların boşanma oranını kalıcı bir şekilde etkilediği bir birim kökünün kanıtını da sağlamaktadır. Tüm kalıcı şoklar pozitif bulunmuş ve çoğu 1970'lerde gruplanmıştır. Bu şoklar o sırada Avrupa'da yaşanan önemli boşanma yasası reformları ile bağlantılı olabilir. Bu reformlar, boşanma politikalarının Avrupa boşanma oranlarının hareketinde önemli bir rol oynadığını göstermektedir.

Smith, Maas ve Tubergen (2012), yeni evli farklı ve aynı etnik gruptan olan çiftler arasında boşanma olayını tanımlamak ve açıklamak için 1995-1998 yılları arasındaki Hollanda'nın nüfus verilerini kullanmışlardır. Yazarlara göre Homojami teorisi ile uyumlu olarak, özellikle eşler birbirlerinden kültürel olarak uzakta olan ülkelerde doğup büyümüş ise, boşanma riski, farklı etnik gruptan olan çiftler için daha yüksektir. Buna ek olarak, kültürel farkın etkisi birinci nesil göçmenlere göre ikinci kuşak göçmenler için daha düşüktür. Afrika kökenli ve Avrupa kökenli evlilikler arasında boşanma riskinin yüksek olduğuna dair bir kanıt bulunmamaktadır. Yakınsama teorisiyle uyumlu olarak, sonuçlar, eşin (kadın) ülkesinde boşanma eğilimi ne kadar yüksekse, bir çiftin boşanma riskinin o kadar yüksek olduğunu göstermektedir.

Wagner ve Weiß (2006), evlilik öncesi birlikte yaşamanın, çocukların varlığının ve ebeveyn boşanma deneyiminin evlilik istikrarı üzerindeki etkilerine odaklanmıştır. Yazarlar, boşanma riskleri üzerine yapılış 260 'dan fazla çalışma tespit edilebilirken, 120 tanesi ileri meta-analitik araştırma için kullanılmış ve boşanma risklerinin ülkeler arasında ve içerisinde önemli derecede heterojen olduğunu göstermiştir. Avrupa ülkeleri arasındaki etki boyutlarının çeşitliliğini açıklamak suretiyle, daha sıkı evlilik normlarının geçerli olduğu ülkelerde birlikte yaşamanın, evlilik istikrarında evlilik normlarının daha zayıf olduğu ülkelerden daha güçlü bir etkisi olduğu gösterilmiştir. Ayrıca, yazarlara göre boşanma engelleri ne kadar düşükse, ebeveyn boşanma ve çocukların boşanma riski arasındaki ilişki o kadar zayıftır.

Giray, S ve Esin F. (2014), intihar oranını etkileyen faktörler açısından 27 Avrupa ülkesinin sınıflandırılması ve benzer yapıda olanlarının saptanması amaçlamıştır. İncelemede; intihar oranı, uzun dönem işsizlik oranı, kişi başına alkol kullanım oran1, doğum oran1, boşanma oranı, evlenme oran1, işgücü katılım oranı gibi değişkenler analize dahil edilmiş ve intihar oranları üzerinde etkili olan değişkenler açısından bulanık kümeleme analizi kullanılarak ülkeler sınıflara ayrılmış ve Türkiye'nin yeri irdelenmiştir.

Özer, U., Topal, M.H., (2017); Türkiye'de genç işsizliğinin suç, göç, intihar ve boşanmalar gibi diğer toplumsal sorunlar üzerinde etkili olup olmadığının ampirik olarak incelemeyi amaçlamaktadır. Analizlerde, Türkiye'nin 26 bölgesinin 20042016 dönemi verileri kullanılmıştır. Panel en küçük kareler tahmin sonuçlarına göre, genç işsizlik suç, göç, intihar ve boşanmalar üzerinde istatistiksel olarak anlamlı ve pozitif yönde etkili olduğu ortaya çıkarılmıştır. 


\section{Veri ve Yöntem}

1996-2007 dönemi Avrupa Birliği’nin (AB) 27 üyesi için yıllık kaba boşanma hızı verileri Aile ve Sosyal Araştırmalar Genel Müdürlüğü'nün 2009 yılındaki boşanma nedenleri araştırmasından ve 2000-2015 verileri de Eurostat (2017)'den elde edilmiştir. $\mathrm{Bu}$ verilerin birleşimi bu makalenin verisini oluşturmaktadır. $\mathrm{Bu}$ veriler geçiş kodları ile birlikte Ek A Tablo A1'de verilmiştir.

Kıral ve Mavruk (2017) çalışmasında kullanılan Markov yöntemi takip edilmiştir. Mevcut verilerin değişimine bağlı olarak boşanma oranları büyükten küçüğe $A, B$, $C$, D ve $E$ olarak beş, $A, B, C$ ve D olarak dört, $A, B$ ve $C$ olarak üç ve $A$ ve $B$ olarak 2 kategoride kodlanabilir. Ek Tablo A1'de gösterildiği gibi bu kodlar arasındaki geçişler yapılır. Ek Tablo A2'de gösterildiği gibi boşanma oranlarının frekans ve olasılık dağılımı kategorilere göre yapılır. Daha sonra da 2018 ve sonrası için boşanma hızları tahminlenir. $n$ yılına kadar geçiş olasılıkları matrisi $P_{n}$ ve $n$ yılı başlangıç olasılık matrisi $Q_{n}$ olmak üzere 2016 yılından itibaren gerçekleşme oranlarını tahminleyen matris

$$
\hat{Q}_{n+1}=\hat{Q}_{n} P_{n}
$$

veya

$$
\hat{Q}_{n+k}=Q_{n} P_{n}^{k}
$$

formülü ile hesaplanabilir. 2015 yılı için $n$ indisini 15 kabul edersek Markov modeli için başlangıç olasılık matrisi $Q_{15}$ ile gösterilir. 2016 yılı tahmini

$$
\hat{Q}_{16}=Q_{15} P_{15}
$$

formülü ile bulunur. 2017 yılı tahmini $\hat{Q}_{17}=\hat{Q}_{16} P_{15}$ matris çarpımı ile bulunabilir. Buradan 2018 yılı tahmini

$$
\hat{Q}_{18}=\hat{Q}_{17} P_{15}=\hat{Q}_{16} P_{15} P_{15}=Q_{15} P_{15} P_{15} P_{15}=Q_{15} P_{15}{ }^{3}
$$

ile hesaplanabilir. $n$ arttıkça $\widehat{Q}_{n+1}$ oranların sabitlendiği durağan bir matrise yakınsar. Bu matrisin durağanlaştığı ilk yıl durağanlık yılı olarak alınır.

\section{Markov Yöntemiyle Boşanma Hızı Tahminleri}

2015 boşanma hızı 1,69 gerçekleştiğinden A kategorisine düşer ve $Q_{15}$ $=\left[\begin{array}{llll}1 & 0 & 0 & 0\end{array}\right]$ olarak yazılabilir.

Eurostat verilerine göre 1996-2015 döneminde Türkiye'de en düşük boşanma hızı 1,35 ve en yüksek boşanma hızı 1,70 olarak gerçekleşmiştir. Dolayısıyla, EkA Tablo A2'de gösterildiği gibi geçiş olasılık matrisi için model dört kategoride oluşturulmuş ve Ek A Tablo A1'deki geçiş kodları bu kategorilere göre düzenlenmiştir. (2) numaralı formülden 2018 yılı tahmini Tablo 1'teki gibi hesaplanmıştır. 
Tablo 1: Türkiye 2018 BH Tahmini

\begin{tabular}{lcc}
\hline $\mathrm{GO}(\%)$ & $\mathrm{Kod}$ & $\mathrm{BH}$ \\
\hline $1,65 \leq r$ & $\mathrm{~A}$ & 1 \\
$1,55 \leq r \leq 1,64$ & $\mathrm{~B}$ & 0 \\
$1,45 \leq r \leq 1,54$ & $\mathrm{C}$ & 0 \\
$r \leq 1,44$ & $\mathrm{D}$ & 0 \\
\hline
\end{tabular}

AB 2018 boşanma oranları tahminleri (2) numaralı formülden hesaplanarak Tablo 2 'te verilmiştir. Kategori sayıları verilerin değişimine bağlı olarak oluşturulmuştur.

Durağanlık tahminleri (2) numaralı formülünden elde edilebilir. Her ülke için bulunan boşanma oranlarının durağanlık matrisleri Tablo 3 'te verilmiştir. Tablo 3'te DY olasılık matrisinin durağan olduğu yıldır.

\subsection{Modelin İstatistiksel Anlamlılığı}

Hollanda ve Romanya için modelin geçerliliği 2015 yılı için test edilmiştir. Modelin geçerliliğini test etmek için Ki-kare test istatistiği

$$
\chi^{2}=\sum_{i=1}^{3} \frac{\left(r_{i}-\hat{r}_{i}\right)^{2}}{\hat{r}_{i}}
$$

kullanılmıştır. 2015 y1lı için hesaplanan matris $\widehat{Q}_{15}=\left[\begin{array}{lll}1 / 7 & 4 / 7 & 2 / 7\end{array}\right]$ ve 2015 yılı boşanma hızı gerçekleşme matrisi $Q_{15}=\left[\begin{array}{lll}0 & 1 & 0\end{array}\right]$ 'dır.

Serbestlik derecesi (sd) 3-1=2' dir. $\chi^{2}$ kritik değeri $\chi^{2}(2,0.05)=5,99$ 'dur. $\chi^{2}$ test değeri

$$
\begin{aligned}
& \chi^{2}=\frac{(0-1 / 7)^{2}}{1 / 7}+\frac{(1-4 / 7)^{2}}{4 / 7}+\frac{(0-2 / 7)^{2}}{2 / 7} \\
&=1 / 7+\left(\frac{9}{49}\right)\left(\frac{7}{4}\right)+2 / 7=0,75 .
\end{aligned}
$$

$\chi^{2}$ test değeri kritik değerden küçük olduğundan $(0,75<5,99)$ sıfır hipotezi reddedilmemiştir. $\mathrm{Bu}$ da hesaplanan gerçekleşme oranları ile gerçek oranlar arasında anlamlı bir fark olmadığını gösterir. Diğer bir ifade ile model geçerlidir.

Benzer şekilde Slovenya 2015 yılı boşanma hızı için hesaplanan matris $\widehat{Q}_{15}=\left[\begin{array}{lll}1 / 7 & 3 / 7 & 3 / 7\end{array}\right]$ ve 2015 yılı boşanma hızı gerçekleşme matrisi $Q_{15}=\left[\begin{array}{lll}0 & 1 & 0\end{array}\right]^{\prime}$ dır. $\chi^{2}$ test değeri

$$
\begin{aligned}
\chi^{2}=\frac{(0-1 / 7)^{2}}{1 / 7}+ & \frac{(1-3 / 7)^{2}}{3 / 7}+\frac{(0-3 / 7)^{2}}{3 / 7} \\
& =1 / 7+\left(\frac{16}{49}\right)\left(\frac{7}{3}\right)+2 / 7=1,19 \text { 'dur. }
\end{aligned}
$$

$\chi^{2}$ test değeri kritik değerden küçük olduğundan $(1,19<5,99)$ sıfır hipotezi reddedilmemiştir. 
Tablo 2: AB 27 ve Türkiye 2018 Boşanma Oranları Tahmini

\begin{tabular}{|l|ccccc|l|lllll|}
\hline & $\mathbf{A}$ & $\mathbf{B}$ & $\mathbf{C}$ & $\mathbf{D}$ & $\mathbf{E}$ & & $\mathbf{A}$ & $\mathbf{B}$ & $\mathbf{C}$ & $\mathbf{D}$ & $\mathbf{E}$ \\
\hline Belçika & 0 & 0 & 0 & 0 & 1 & Bulgaristan & 0,08 & 0,28 & 0,64 & 0 & \\
\hline Çek Cum. & 0,02 & 0,18 & 0,46 & 0,44 & & Danimarka & 0,17 & 0 & 0,58 & 0,25 & \\
\hline Almanya & 0,01 & 0,08 & 0,53 & 0,38 & & Estonya & 0,08 & 0 & 0,25 & 0,27 & 0,40 \\
\hline İrlanda & 0,13 & 0,87 & 0 & 0 & 0 & Yunanistan & 0,18 & 0,38 & 0,37 & 0,07 & 0 \\
\hline İspanya & 1 & 0 & 0 & 0 & 0 & Fransa & 0,03 & 0 & 0,17 & 0,80 & \\
\hline Hirvatistan & 0,12 & 0,16 & 0,72 & 0 & & Italya & 1 & 0 & 0 & 0 & \\
\hline G.Kıbris & 0,36 & 0,64 & 0 & 0 & & Litvanya & 0,25 & 0,58 & 0,17 & \\
\hline Letonya & 0,08 & 0,28 & 0,11 & 0,33 & 0,20 & Lüksemburg & 0,06 & 0,35 & 0,40 & 0,19 & \\
\hline Macaristan & 0 & 0 & 1 & & & Hollanda & 0,04 & 0,35 & 0,61 & \\
\hline Avusturya & 0 & 0 & 0 & 1 & & Polonya & 0,13 & 0,87 & 0 & 0 \\
\hline Portekiz & 0,16 & 0,84 & 0 & 0 & 0 & Romanya & 0,06 & 0,48 & 0,46 & \\
\hline Slovenya & 0,06 & 0,48 & 0,46 & & & Slovakya & 0,08 & 0,28 & 0,65 & \\
\hline Finlandiya & 0,26 & 0,74 & & & & İsveç & 0,06 & 0,07 & 0,60 & 0,27 & \\
\hline İngiltere & 0,16 & 0,60 & 0 & 0,24 & & Türkiye & 1 & 0 & 0 & 0 & \\
\hline
\end{tabular}

Finlandiya 2015 y1lı boşanma hızı için hesaplanan matris $\hat{Q}_{15}=\left[\begin{array}{ll}1 / 7 & 6 / 7\end{array}\right]$ ve 2015 yılı boşanma hızı gerçekleşme matrisi $Q_{15}=\left[\begin{array}{ll}0 & 1\end{array}\right]$ ' dır. $\chi^{2}$ test değeri

$$
\begin{aligned}
& x^{2}=\frac{(0-1 / 7)^{2}}{1 / 7}+\frac{(1-6 / 7)^{2}}{6 / 7} \\
& =1 / 7+\left(\frac{1}{49}\right)\left(\frac{7}{6}\right)=0,17^{\prime} \text { dir. }
\end{aligned}
$$

$\chi^{2}$ test değeri kritik değerden küçük olduğundan $(0,17<3,84)$ sifır hipotezi reddedilmemiştir.

Litvanya 2015 y1lı boşanma hızı için hesaplanan matris $\widehat{Q}_{15}=\left[\begin{array}{lll}2 / 9 & 5 / 9 & 2 / 9\end{array}\right]$ ve 2015 yılı boşanma hızı gerçekleşme matrisi $Q_{15}=\left[\begin{array}{lll}0 & 1 & 0\end{array}\right]$ 'dır. $\chi^{2}$ test değeri

$$
\begin{aligned}
\chi^{2}=\frac{(0-2 / 9)^{2}}{2 / 9}+\frac{(1-5 / 9)^{2}}{5 / 9}+\frac{(0-2 / 9)^{2}}{2 / 9} & \\
=2 / 9+\left(\frac{36}{81}\right)\left(\frac{9}{5}\right)+2 / 9=1,24 & \text { 'tür. }
\end{aligned}
$$


Tablo 3: Boşanma Oranı Durağanlığ1

\begin{tabular}{|c|c|c|c|c|c|c|c|c|c|c|c|}
\hline \multirow[b]{2}{*}{ Belçika } & \multicolumn{5}{|c|}{ Başlangıç Olasılık Matrisi } & \multicolumn{5}{|c|}{$\lim _{n \rightarrow \infty} \hat{Q}_{n}=\hat{Q}$} & \multirow{2}{*}{$\begin{array}{l}D Y \\
2017 \\
\end{array}$} \\
\hline & 0 & 0 & 0 & 0 & 1 & 0 & 0 & 0 & 0 & 1 & \\
\hline Çek. Cum. & 0 & 0 & 0 & 1 & & 0,0377 & 0,3019 & 0,3775 & 0,2831 & & 2036 \\
\hline Almanya & 0 & 0 & 0 & 1 & & 0,0689 & 0,1724 & 0,5517 & 0,2069 & & 2044 \\
\hline İrlanda & 0 & 1 & 0 & 0 & 0 & 0,1429 & 0,8571 & 0 & 0 & 0 & 2027 \\
\hline İspanya & 1 & 0 & 0 & 0 & 0 & 1 & 0 & 0 & 0 & 0 & 2017 \\
\hline Hirvatistan & 1 & 0 & 0 & 0 & & 0,1429 & 0,2143 & 0,6429 & 0 & & 2030 \\
\hline G.Kıbris & 0 & 1 & 0 & 0 & & 0,3636 & 0,6364 & 0 & 0 & & 2021 \\
\hline Letonya & 0 & 0 & 0 & 1 & 0 & 0,0588 & 0,1765 & 0,1176 & 0,4118 & 0,2353 & 2031 \\
\hline Macaristan & 0 & 0 & 1 & & & 0 & 0 & 1 & & & 2017 \\
\hline Avusturya & 0 & 0 & 0 & 1 & & 0 & 0 & 0 & 1 & & 2017 \\
\hline Portekiz & 0 & 1 & 0 & 0 & 0 & 0,1579 & 0,8421 & 0 & 0 & 0 & 2021 \\
\hline Slovenya & 0 & 1 & 0 & & & 0,0588 & 0,4706 & 0,4706 & & & 2023 \\
\hline Finlandiya & 0 & 1 & & & & 0,36 & 0,64 & & & & 2036 \\
\hline İngiltere & 0 & 1 & 0 & 0 & & 0,1333 & 0,5333 & 0 & 0,3333 & & 2043 \\
\hline Bulgaristan & 0 & 0 & 1 & 0 & & 0,1000 & 0,3000 & 0,6000 & 0 & & 2025 \\
\hline Danimarka & 0 & 0 & 1 & 0 & & 0,1538 & 0 & 0,5385 & 0,3077 & & 2041 \\
\hline Estonya & 0 & 0 & 0 & 1 & 0 & 0,1200 & 0 & 0,2400 & 0,2400 & 0,4000 & 2050 \\
\hline Yunanistan & 0 & 1 & 0 & 0 & 0 & 0,1111 & 0,3334 & 0,3889 & 0,1389 & 0,0278 & 2040 \\
\hline Fransa & 0 & 0 & 0 & 1 & & 0,0588 & 0 & 0,2941 & 0,6471 & & 2045 \\
\hline Italya & 1 & 0 & 0 & 0 & & 1 & 0 & 0 & 0 & & 2017 \\
\hline Litvanya & 0 & 1 & 0 & & & 0,2553 & 0,5745 & 0,1702 & & & 2023 \\
\hline Lüksemburg & 0 & 1 & 0 & 0 & & 0,0625 & 0,3750 & 0,3750 & 0,1875 & & 2026 \\
\hline Hollanda & 0 & 0 & 1 & & & 0,0476 & 0,3809 & 0,5714 & & & 2027 \\
\hline Polonya & 0 & 1 & 0 & 0 & & 0,1250 & 0,8750 & 0 & 0 & & 2020 \\
\hline Romanya & 0 & 1 & 0 & & & 0,0588 & 0,4706 & 0,4706 & & & 2028 \\
\hline Slovakya & 0 & 0 & 1 & & & 0,1429 & 0,3571 & 0,50 & & & 2050 \\
\hline İsveç & 0 & 0 & 1 & 0 & & 0,06 & 0,06 & 0,59 & 0,29 & & 2026 \\
\hline Türkiye & 1 & 0 & 0 & 0 & & 1 & 0 & 0 & 0 & & 2017 \\
\hline
\end{tabular}


$\chi^{2}$ test değeri kritik değerden küçük olduğundan $(1,24<5,99)$ sıfir hipotezi reddedilmemiştir.

Modelin geçerliliği her ülke için daha düşük kategori sayıları kullanılarak gösterilebilir. Seçilen kategori sayılarına göre bazı ülkelerin 2015 yılı için model geçerliliği Tablo 4'da gösterilmiştir.

Tablo 4: Boşanma Oranları Modellerinin Geçerliliği

\begin{tabular}{|c|c|c|c|c|}
\hline \multirow[b]{2}{*}{ Ülkeler } & \multicolumn{4}{|c|}{2015} \\
\hline & $\mathrm{sd}$ & $X_{0,05}^{2}$ Kritik Değer & $X_{0,05}^{2}$ Test Değeri & $\mathrm{H}_{0}$ : Geçerli \\
\hline Slovenva & 2 & 5.991 & 1.19 & Kabul \\
\hline Finlandiva & 1 & 3,841 & 0,17 & Kabul \\
\hline Litvanva & 2 & 5.991 & 1.24 & Kabul \\
\hline Hollanda & 2 & 5.991 & 0.75 & Kabul \\
\hline Romanya & 2 & 5,991 & 0,75 & Kabul \\
\hline
\end{tabular}

\section{Bulgular}

Son demografik veriler, her 1.000 kişide boşanma sayısının AB 27 ve Türkiye'de son yıllarda arttığını göstermektedir. 2015 yılında en yüksek kaba boşanma hızı Litvanya ve Danimarka'da \%3,2 ve \%2,9 olarak gerçekleşmiştir. Bu oranlar ortalamanın yaklaşık bir puan üzerindedir. Diğer taraftan en düşük boşanma hızı İrlanda ve İtalya'da 0,7 ve 0,9 olarak gerçekleşmiştir. 2014 y1lından 2015 yılına en yüksek artış 0,5 ile İtalya'da ve en yüksek düşüş yine aynı oranla Letonya' da gerçekleşmiştir. 48 yıl önce boşanma yasalaştıktan sonra İtalya'da boşanma hızı her on yılda 0,2 artarak 2010 yılında 0,9'a ulaşmıştır. Bu oran 2014 yılına kadar sabit kalmış ancak 2015 yılında 0,5 sıçrama yaparak 1,4'e yükselmiştir. Bu sıçrama üye ülkeler arasında en yüksek boşanma hızı artışını göstermektedir. Boşanma yasalaştıktan on yıl sonra İspanya'da boşanma hızı İtalya'dakinden üç kat daha fazla gerçekleşmiştir. İspanya'da boşanma hızı 2010 yılına kadar her on yılda 0,3 artarak 2,2'e yükselmiştir ve durağan bir davranış göstererek 2015 yılında 2,1 olarak gerçekleşmiştir. İrlanda' da boşanma yasalaştıktan beş yıl sonra boşanma hızı 0,7 oranına ulaşmıştır. Malta' da boşanma 2011'de yasalaştıktan bir yıl sonra 1 puan artışla boşanma hızı 1,1 olarak gerçekleşmiş ve bu oran bir yılda en yüksek boşanma hızı artış oranını göstermektedir. Bu oran daha sonra 0,8'e gerileyerek en son 2015 yılında 0,9 olarak gerçekleşmiştir. EU 27 ortalama kaba boşanma hızı 1996 yılında 1,89'dan 2015 yılında 2,04'e \%8 artış göstermiştir. Aynı periyot üzerinde Türkiye boşanma hızı artışı yaklaşı \% \%23'tür.

Kuzey Avrupa'da iki komşu ülke Danimarka ve İsveç'te boşanma oranları birbirine yakın ve benzer davranış göstermektedir. Kuzeydoğu Avrupa'da komşu iki ülke Letonya ve Litvanya'da boşanma oranları benzer şekilde hareket etmektedir. Aynı bölgede diğer iki yakın ülke Finlandiya (2,4-2,7 bandında) ve 
Estonya (2,2-4,0 bandında) benzer şekilde azalmaktadır. İngiltere (1,9-3,0 bandında) ve Estonya komşu olmayan iki ülke olarak daha çok benzer davranış göstermektedir. Orta Avrupa'da Belçika, Almanya ve Macaristan benzer davranışa sahiptir. Fransa da 2005 artışından oluşan tepe yontulursa bu ülkelere dahil edilebilir. Aynı bölgede Avusturya bu üç ülkeye az benzer bir davranış gösterse de 2001'deki tepe yontulursa Fransa, Slovakya ve Slovenya'ya daha çok benzer bir davranış göstermektedir. Benzer şekilde 1999'daki minimum nokta hariç Çek Cumhuriyeti ve ayrıca Bulgaristan da bu ülkelere benzer davranış göstermektedir. Bununla birlikte Fransa diğerlerine göre daha yatay bir davranış göstermektedir. Lüksemburg, komşuları Almanya, Fransa ve Belçika'dan farklı olarak daha çok Danimarka ve İsveç'e benzer bir davranış göstermektedir. Durağanlık açısından bakıldığında Lüksemburg, Hollanda, İlanda ve Romanya benzer davranış göstermekte ve bütün ülkeler arasında en durağan olanı $(2,0$ civarında) Hollanda'dır. Güneydoğu Avrupa'da Yunanistan, Hırvatistan ve Güney Kıbrıs benzer davranış göstermektedir.

Türkiye daha çok İsveç ve Danimarka'ya benzer şekilde yatay hareketten sonra artı̧̧ göstermektedir.

1996-2004 döneminde \%7 artan ve 2004 yılındaki tepe noktasından itibaren azalmaya başlayan Belçika boşanma oranı 2010-2015 döneminde yaklaşık \%18,5 azalmıştır. Genel olarak 1996-2015 döneminde \%21,4 azalış göstermektedir. 1996-2007 döneminde \%75 artan ve 2007-2010 döneminde \%33,3 azalan Bulgaristan boşanma oranı 2010-2015 döneminde 1,5 civarında durağanlık göstermiştir. Genel olarak 1996-2015 döneminde \%25 artış göstermektedir. 19962004 döneminde \%20,1 artan, 2004-2006 döneminde \%10,3 azalan ve 2006-2011 döneminde sabit 2,6 olan Danimarka boşanma oranı 2011-2014 döneminde \%30,8 artış göstermiş ve 2014-2015 döneminde \%14,7 azalmıştır. Genel olarak 19962015 döneminde \%20,1 artış göstermektedir. Çek Cumhuriyeti'nde 1996-1999 döneminde \%28,1 azalış, 1999-2003 döneminde \%65,2 artış gösteren boşanma oran1 2003-2015 döneminde \%34,2 ve 2010-2015 döneminde yaklaşı \%13,8 azalmıştır. Genel olarak 1996-2015 döneminde \%21,9 azalış göstermektedir. Almanya'da 1996-2004 döneminde \%23,8 artış ve 2004-2015 döneminde \%23,1 azalış göstermektedir. Genel olarak 1996-2015 döneminde \%4,7 azalış göstermektedir. Estonya'da 1996-2010 döneminde \%45 azalış ve 2010-2015 döneminde \%18,2 artış göstermektedir. Genel olarak 1996-2015 döneminde \%35 azalış göstermektedir. İrlanda'da 1996 yılında boşanmanın yasal hale gelmesiyle tepki vermese de 2005 yılına kadar binde 0,8 artış göstermiş ancak kilise ve hükümetin boşanmayı caydırıcı politikası nedeniyle 2013 yılına kadar 0,2 düşüş göstermiş ve 2015 yılına kadar 0,1 artış göstermiştir. Yunanistan'da 1996-1998 döneminde \%22,2 düşüş gösteren boşanma oranı 1998-2013 döneminde \%114,3 artı̧̧ ve 2013-2015 döneminde \%13.3 azalış göstermektedir. Genel olarak 19962015 döneminde \%44,4 artış göstermektedir. İspanya'da boşanma oran1 20062007 hariç 1996-2012 döneminde sürekli artışla \%175 artış göstermektedir. 20122015 döneminde ise 2,1 civarında durağanlık göstermektedir. 
Tablo 5: Markov Tahminlerine Göre Boşanma Hızı

\begin{tabular}{|c|c|c|c|c|}
\hline $\begin{array}{l}\text { AB } 27 \text { ve } \\
\text { Türkiye }\end{array}$ & $\begin{array}{l}2018 \text { Olasılık } \\
(\%)\end{array}$ & $\begin{array}{c}\text { Durağanlık } \\
(\%)\end{array}$ & $\begin{array}{l}\text { Boşanma Hızı, } \\
r(\% 0)\end{array}$ & $\begin{array}{c}\text { AB } 272015 \\
\text { Ortalamasının } \\
\text { Altı/Üstü(-/+) }\end{array}$ \\
\hline Belcika & 100 & 100 & $2.2 \leq r \leq 2.3$ & + \\
\hline Cek Cum. & 44 & 28 & $2.3<r<2.6$ & + \\
\hline Almanya & 38 & 21 & $2,0 \leq r \leq 2,1$ & - \\
\hline İrlanda & 86 & 86 & $0.6<r<0.7$ & - \\
\hline İspanya & 100 & 100 & $2,0 \leq r \leq 2,2$ & $-/+$ \\
\hline Hirvatistan & 72 & 64 & $1.0<r<1.1$ & - \\
\hline Kibris & 64 & 64 & $1,9 \leq r \leq 2,2$ & $-/+$ \\
\hline Letonva & 20 & 24 & $2.1<r<2.4$ & + \\
\hline Macaristan & 100 & 100 & $2,0 \leq r \leq 2,1$ & - \\
\hline Avusturva & 100 & 100 & $1.9<r<2.0$ & - \\
\hline Portekiz & 84 & 84 & $2,2 \leq r \leq 2,4$ & + \\
\hline Slovenva & 48 & 47 & $1.2<r<1.3$ & - \\
\hline Finlandiva & 74 & 64 & $2.4 \leq r \leq 2.5$ & + \\
\hline İngiltere & 24 & 33 & $1.9<r<2.1$ & - \\
\hline Bulgaristan & 92 & 90 & $1,1 \leq r \leq 1.9$ & - \\
\hline Danimarka & 25 & 31 & $2.4<r<2.6$ & + \\
\hline Estonva & 40 & 40 & $2.2<r<2.5$ & + \\
\hline Yunanistan & 38 & 33 & $1.3<r<1.4$ & - \\
\hline Fransa & 80 & 65 & $1,9 \leq r \leq 2,0$ & - \\
\hline Italva & 100 & 100 & $0.9<r<1.0$ & - \\
\hline Litvanva & 58 & 57 & $3.2<r<3.3$ & + \\
\hline Lüksemburg & 19 & 19 & $2.0<r<2.1$ & - \\
\hline Hollanda & 61 & 57 & $1.9 \leq r \leq 2,0$ & - \\
\hline Polonva & 100 & 100 & $1.6<r<2.1$ & - \\
\hline Romanva & 48 & 47 & $1.6<r<1.7$ & - \\
\hline Slovakva & 65 & 50 & $1,7 \leq r \leq 1,9$ & - \\
\hline İsveç & 60 & 59 & $2,3 \leq r \leq 2,5$ & + \\
\hline Türkiye & 100 & 100 & $1,65 \leq r \leq 1,74$ & - \\
\hline
\end{tabular}

Genel olarak 1996-2015 döneminde \%162,5 artış göstermektedir. Fransa'da boşanma oranı 1996-2005 döneminde \%25 artış ve 2005-2015 döneminde ise \%24 azalış göstermektedir. Hırvatistan'da boşanma oranı 1996-2015 döneminde \%75 artmıştır. İtalya'da 1996-2014 döneminde 18 yılda \%50 artış gösteren boşanma oranı 2014'ten 2015'e bir yılda \%55,6 artmıştır. Genel olarak 1996-2015 döneminde \%133,3 artı̧ göstermektedir. Kıbrıs'ta 1996-2015 döneminde azalan oranda artan boşanma oranı \%91 artış göstermektedir. Letonya'da 1996-2005 döneminde 2,5 civarında durağan davranış gösteren boşanma oranı 2005-2015 döneminde 3,0 civarında salınarak 4'te tepe yapmıştır. Bu oran 1996-2015 
döneminde Avrupa Birliği'nde gerçekleşen en yüksek boşanma oranıdır. Litvanya boşanma oranı 2003 yılından itibaren farklı oranlarda ancak Letonya'nınkine benzer bir davranış göstermektedir. 1996-2003 döneminde azalan zig-zaglar yapan oranlar 2003-2015 döneminde artan zig-zaglar yaparak neredeyse 1996 yılında başladığı orana 2015 yılında geri gelmiştir. 2012-2015 döneminde \%8,6 azalmıştır. Lüksemburg'da boşanma oranı 2,3 civarında yatay seyretmektedir. Macaristan'da boşanma oranları 1996-2015 döneminde 2,0-2,5 arasında yatay hareket etmektedir. Benzer şekilde Hollanda'da boşanma oranları 2,0 civarında durağanlık göstermektedir. Avusturya 1,9-2,6 arasında yatay hareket etmektedir. Polonya 1996-2006 periyodunda \%90 artış göstermektedir. Daha sonra 2015 yılına kadar 1,7 civarında yatay seyretmektedir. Portekiz 1996-2002 periyodunda $\% 107,7$ artış, bir y1l sonra da \%18,5 düşüş göstermiştir. Daha sonra \%18,2 artışla 2006 yılında 2,6 ile yatay bir tepe yaparak 2015 yılında 2,4'te kalmıştır. Slovenya 1996-2007 periyodunda \%40 artıştan sonra 2007-2015 periyodunda \%14,3 azalmıştır. Romanya 1,5 civarında durağan hareket etmektedir. Finlandiya'da boşanma oranları aşağı yönlü "V" li basamaklar yapmıştır. 2012 yılına kadar \%11 azalan oranlar 2013 yılında 0,1 artarak 2015 yılına kadar sabit kalmıştır. Slovakya 1996-2006 periyodunda \%41,2 artan boşanma oranı 2006-2015 periyodunda \%25 azalmıştır. İsveç'te boşanma oranları 2,5 'in hemen altında yatay bir hareketten sonra 2,5'i yukarıya doğru keserek 2013 yılında 2,8 ile küçük bir tepe yaparak 2015 yılında tekrar 2,5'e geri gelmiştir. İngiltere'de boşanma oranları 1996'da binde 3'ten 2014'te binde 1,9'a kadar aşağı yönlü hareketle \%36,7 azalmıştır. 2015 yilında \%31,6 artmıştır.

Türkiye'de boşanma oranları 1996'dan 2007 yılına kadar 1,4 civarında yatay hareketten sonra yıllık ortalama \%4,38 artışla 2015 yılına kadar \%26 artış göstermektedir.

Tablo 5'de gösterildiği gibi Markov tahminlerimize göre kısa ve uzun vadede Belçika boşanma oranı \%100 olasılıkla binde 2,2-2,3'ün aralığında gerçekleşecektir. Bu oranlar AB 272015 ortalaması olan 2,1'in üzerindedir. Ayrıca 1996-2015 periyodunda boşanma oranları AB 272015 ortalamasının üzerinde gerçekleşmiştir. Türkiye'de boşanma oranı kısa ve uzun vadede $\% 100$ olasılıkla binde 1,65 'in üzerinde gerçekleşecektir. Benzer şekilde diğer ülkelerin boşanma hızı tahminleri Tablo 5'de verilmiştir.

\section{Tartışma ve Sonuç}

AB 27 kaba boşanma hızları 1996-2015 Eurostat verilerine dayanılarak hesaplanmıştır. En yüksek AB 27 ortalaması 2006 ve 2007'de binde 2,3 olarak gerçekleşmiştir. Bir yılda en hızlı artış 2010-2011 döneminde \%67 ile Letonya'da gerçekleşmiştir. Kuzey ve Kuzeydoğu Avrupa'daki ülkelerin kaba boşanma hızlarının AB 27 ortalamasının üstünde olduğu tespit edilmiştir. Ayrıca bu bölgelerde komşu ülkelerin boşanma oranlarının benzer davranışlar gösterdiği sonucuna varılmıştır. Bu ülkeler arasında 2015 yılında en yüksek boşanma hızı Litvanya'da gerçekleşmiştir. Aynı yılda en düşük boşanma hızının da İrlanda'da 
gerçekleştiği tahmin edilmektedir. İrlanda'da yasama boşanmayı kolaylaştırıcı düzenleme yapmaz ise evlilik dişı çocuk yapma oranları yükselmeye devam edecektir. 2011-2015 döneminde en hızlı düşüş \%35 ile Letonya'da ve en hızlı artış \%56 ile İtalya'da gerçekleşmiştir.

Geçiş matrisleri boşanma oranları geçişlerinin durağanlığa varan süreçte yüksek kategorilerden düşük kategorilere azaldığı ve düşük kategorilerden yüksek kategorilere arttığı görülmektedir. Beş kategori ile oluşturulan Markov modellerine göre, Yunanistan hariç, başlangıç boşanma olasılı̆̆ 1 üst kategorilerde olan ülkelerin boşanma hızının üst kategorilerde ve başlangıç olasılığı alt kategorilerde olan ülkelerin boşanma hızının ise alt kategorilerde durağanlaşacağı sonucuna varılmıştır. Dört kategori ile oluşturulan Markov modellerine göre 2018 boşanma oranlarının büyük olasılıkla daha çok alt kategorilerde gerçekleşeceği ve ileri yıllarda yine alt kategorilerde durağanlaşacağı sonucuna varılmıştır. Aynı sonuç üç kategorili Markov modelleri için de geçerlidir.

AB 27 kaba boşanma hızlarının hükümetlerin boşanma politikalarıyla 1996-2015 döneminde ortalama binde 2,0-2,3 bandında kontrol edildiği veya dengede tutulduğu görülmektedir. Elde ettiğimiz kesin sonuçlara göre sadece Belçika kaba boşanma hızı 2015 ortalamasının üstünde ve Macaristan, Avusturya, İtalya ve Polonya boşanma hızları ise 2015 ortalamasının altında gerçekleşecek ve durağanlaşacaktır. Büyük olasılıkla İrlanda, Hırvatistan, Bulgaristan, Fransa, Hollanda ve Slovakya 2018 kaba boşanma hızı 2015 ortalamasının altında gerçekleşecek ve durağanlaşacaktır.

Türkiye' de kaba boşanma hızı 2007-2015 döneminde \%26, yıllık ortalama \%3,26 artış göstermiştir. $\mathrm{Bu}$ artışın sabit olacağı varsayılırsa altı yılda AB 27 ortalamasının yakalanacağı kesindir. Nitekim Türkiye'de gerçek evliliklerden, mahkeme ertelemeleri haricinde, boşanmayı engelleyici bir politika bulunmamaktadir.

AB 27 de boşanmayı engelleyici politikaların farklı sorunlar ortaya çıkardığ 1 görülmektedir. Bu politikalar azaldıkça ebeveynlerin boşanma riski azalacak ve evlilik dışı çocuk yapma sayısı düşecektir. Boşanma maliyetinin yüksek olması evlilik sayısının azalmasına ve birlikte yaşamaya yönelmeye neden olabilir. Diğer taraftan evlilik öncesi birlikte yaşama boşanma riskini arttıracaktır.

\section{Kaynakça}

Balestrino, A., Ciardi, C., ve Mammini, C., (2013), "On the Causes and Consequences of Divorce", The Journal of Socieconomics, 45, 1-9.

Crosby, J., F., (1980), “A Critique of Divorce Statistics and Their Interpretation”, Family Relations, 29(1), 51-58.

Eurostat(2017),http://ec.europa.eu/eurostat/statisticsexplained/index.php/File:Cru de_divorce_rate,_selected_years,_1960-2015_(per_1_000_persons).png 
Giray, S., Gülel, F.E. (2014), "Avrupa Ülkelerinin İntihar Oranlarına Göre Sinıflandırılması”, SDU FEF, Sosyal Bilimler Dergisi, 31, 235-247.

González, L. ve Viitanen, T., K., (2009), "The Effect of Divorce Laws on Divorce Rates in Europe", European Economic Review, 53(2), 127-138.

González-Val, R., ve Marcén M., (2012), "Breaks in the Breaks: An Analysis of Divorce Rates in Europe", International Review of Law and Economics, 32(2), 242-255.

Hiller, V., ve Recoules, M., (2013), "Changes in Divorce Patterns: Culture and the Law”, International Review of Law and Economics, 34, 77-87.

Kiral, E., ve Mavruk, C., (2017), “Tax Declaration Rates Via Audits: A Prediction Using Markov Model”, Journal of Business Economics and Finance, 6(2), 97111.

Kneip, T., ve Bauer, G., (2009), "Did Unilateral Divorce Laws Raise Divorce Rates in Western Europe?", Journal of Marriage and Family, 71(3), 592-607.

Meagher, J., (2015), "Why does Ireland have the lowest divorce rate in the EU?" https://www.independent.ie/life/family/family-features/why-does-irelandhave-the-lowest-divorce-rate-in-the-eu-34217513.html

Özer, U., Topal, M.H. (2017), “Genç İşsizliği, Suç, Göç, İntihar ve Boşanma Düzeyleri ile İlişkili midir? Türkiye'den Ampirik Bir Kanıt”, Kırklareli Üniversitesi İktisadi ve İdari Bilimler Fakültesi Dergisi, 6(5), 50-63.

Smith, S., Maas, I., ve Tubergen, F., (2012), "Irrencilable Differences? Ethnic Intermarriage and divorce in the Netherlands, 1995-2008", Social Science Research, 41, 1126-1137.

Wagner, M., ve Weiß, B., (2006), “On The Variation of Divorce Risks in Europe: Findings From a Meta-Analysis of European Longitudinal Studies", European Sociological Review, 22(5), 483-500. 
EKA:

Tablo A1. AB 27 ve Türkiye Boşanma Hızı Verileri

\begin{tabular}{|c|c|c|c|c|c|c|c|c|c|c|c|c|}
\hline & \multicolumn{3}{|c|}{ Belçika } & \multicolumn{3}{|c|}{ Bulgaristan } & \multicolumn{3}{|c|}{ Çek Cum. } & \multicolumn{3}{|c|}{ Danimarka } \\
\hline Yıl & GO & Kod & Geçiş & GO & Kod & Geçiş & GO & Kod & Geçiş & GO & Kod & Geçiş \\
\hline 1996 & 2,8 & B & & 1,2 & $\mathrm{D}$ & & 3,2 & B & & 2,4 & $\mathrm{D}$ & \\
\hline 1997 & 2,6 & $\mathrm{C}$ & $\mathrm{BC}$ & 1,1 & D & $\mathrm{DD}$ & 3,2 & B & $\mathrm{BB}$ & 2,4 & $\mathrm{D}$ & $\mathrm{DD}$ \\
\hline 1998 & 2,6 & C & $\mathrm{CC}$ & 1,3 & D & DD & 3,1 & B & BB & 2,5 & D & DD \\
\hline 1999 & 2,6 & $\mathrm{C}$ & $\mathrm{CC}$ & 1,3 & $\mathrm{D}$ & DD & 2,3 & $\mathrm{D}$ & $\mathrm{BD}$ & 2,5 & $\mathrm{D}$ & $\mathrm{DD}$ \\
\hline 2000 & 2,6 & $\mathrm{C}$ & $\mathrm{CC}$ & 1,3 & $\mathrm{D}$ & $\mathrm{DD}$ & 2,9 & C & DC & 2,7 & $\mathrm{C}$ & $\mathrm{DC}$ \\
\hline 2001 & 2,8 & B & $\mathrm{CB}$ & 1,3 & $\mathrm{D}$ & $\mathrm{DD}$ & 3,1 & B & $\mathrm{CB}$ & 2,7 & $\mathrm{C}$ & $\mathrm{CC}$ \\
\hline 2002 & 3,0 & A & BA & 1,3 & D & DD & 3,1 & B & BB & 2,8 & $\mathrm{C}$ & $\mathrm{CC}$ \\
\hline 2003 & 3,0 & A & AA & 1,5 & $\mathrm{C}$ & DC & 3,8 & A & BA & 2,9 & $\mathrm{C}$ & $\mathrm{CC}$ \\
\hline 2004 & 3,0 & A & AA & 1,9 & B & $\mathrm{CB}$ & 3,2 & B & $\mathrm{AB}$ & 2,9 & C & $\mathrm{CC}$ \\
\hline 2005 & 2,9 & B & $\mathrm{AB}$ & 1,9 & B & $\mathrm{BB}$ & 3,1 & B & $\mathrm{BB}$ & 2,8 & $\mathrm{C}$ & $\mathrm{CC}$ \\
\hline 2006 & 2,8 & B & $\mathrm{BB}$ & 1,9 & B & $\mathrm{BB}$ & 3,1 & B & $\mathrm{BB}$ & 2,6 & $\mathrm{D}$ & $\mathrm{CD}$ \\
\hline 2007 & 2,9 & B & BB & 2,1 & A & BA & 3,0 & $\mathrm{C}$ & $\mathrm{BC}$ & 2,6 & $\mathrm{D}$ & $\mathrm{DD}$ \\
\hline 2010 & 2,7 & $\mathrm{C}$ & $\mathrm{BC}$ & 1,5 & $\mathrm{C}$ & $\mathrm{AC}$ & 2,9 & $\mathrm{C}$ & $\mathrm{CC}$ & 2,6 & D & $\mathrm{DD}$ \\
\hline 2011 & 2,5 & $\mathrm{D}$ & $\mathrm{CD}$ & 1,4 & $\mathrm{C}$ & $\mathrm{CC}$ & 2,7 & $\mathrm{C}$ & $\mathrm{CC}$ & 2,6 & D & $\mathrm{DD}$ \\
\hline 2012 & 2,3 & E & DE & 1,6 & C & $\mathrm{CC}$ & 2,5 & D & CD & 2,8 & C & DC \\
\hline 2013 & 2,2 & E & $\mathrm{EE}$ & 1,5 & C & $\mathrm{CC}$ & 2,7 & C & DC & 3,4 & A & CA \\
\hline 2014 & 2,2 & E & $\mathrm{EE}$ & 1,5 & $\mathrm{C}$ & $\mathrm{CC}$ & 2,5 & $\mathrm{D}$ & $\mathrm{CD}$ & 3,4 & A & AA \\
\hline 2015 & 2,2 & E & $\mathrm{EE}$ & 1,5 & $\mathrm{C}$ & $\mathrm{CC}$ & 2,5 & $\mathrm{D}$ & $\mathrm{DD}$ & 2,9 & $\mathrm{C}$ & $\mathrm{AC}$ \\
\hline \multicolumn{4}{|c|}{ Almanya } & \multicolumn{3}{|c|}{ Estonya } & \multicolumn{3}{|c|}{ İrlanda } & \multicolumn{3}{|c|}{ Yunanistan } \\
\hline Yil & GO & Kod & Geçiş & GO & Kod & Geçiş & GO & Kod & Geçiş & GO & Kod & Geçis \\
\hline 1996 & 2,1 & D & & 4,0 & A & & 0,0 & E & & 0,9 & D & \\
\hline 1997 & 2,3 & $\mathrm{C}$ & DC & 3,8 & A & AA & 0,0 & E & $\mathrm{EE}$ & 0,9 & D & $\mathrm{DD}$ \\
\hline 1998 & 2,3 & C & $\mathrm{CC}$ & 3,2 & $\mathrm{C}$ & AA & 0,4 & $\mathrm{C}$ & $\mathrm{EC}$ & 0,7 & E & $\mathrm{DE}$ \\
\hline 1999 & 2,3 & $\mathrm{C}$ & $\mathrm{CC}$ & 3,3 & $\mathrm{C}$ & $\mathrm{AC}$ & 0,6 & B & $\mathrm{CB}$ & 0,9 & D & ED \\
\hline 2000 & 2,4 & B & $\mathrm{CB}$ & 3,0 & $\mathrm{C}$ & $\mathrm{CC}$ & 0,7 & B & $\mathrm{BB}$ & 1,0 & $\mathrm{D}$ & $\mathrm{DD}$ \\
\hline 2001 & 2,4 & B & $\mathrm{BB}$ & 3,2 & $\mathrm{C}$ & $\mathrm{CA}$ & 0,7 & B & $\mathrm{BB}$ & 1,1 & $\mathrm{C}$ & $\mathrm{DC}$ \\
\hline 2002 & 2,5 & B & BB & 3,0 & $\mathrm{C}$ & $\mathrm{CC}$ & 0,7 & B & $\mathrm{BB}$ & 1,0 & D & $\mathrm{CD}$ \\
\hline 2003 & 2,6 & A & BA & 2,9 & $\mathrm{D}$ & $\mathrm{CD}$ & 0,7 & B & $\mathrm{BB}$ & 1,1 & $\mathrm{C}$ & DC \\
\hline 2004 & 2,6 & A & AA & 3,1 & C & $\mathrm{DC}$ & 0,8 & A & BA & 1,1 & C & $\mathrm{CC}$ \\
\hline 2005 & 2,4 & B & $\mathrm{AB}$ & 3,0 & $\mathrm{C}$ & $\mathrm{CC}$ & 0,8 & A & AA & 1,2 & $\mathrm{C}$ & $\mathrm{CC}$ \\
\hline 2006 & 2,3 & $\mathrm{C}$ & $\mathrm{BC}$ & 2,8 & $\mathrm{D}$ & $\mathrm{CD}$ & 0,7 & B & $\mathrm{AB}$ & 1,3 & B & $\mathrm{CB}$ \\
\hline 2007 & 2,2 & C & $\mathrm{CC}$ & 2,8 & $\mathrm{D}$ & DD & 0,7 & B & BB & 1,2 & C & $\mathrm{BC}$ \\
\hline 2010 & 2,3 & C & $\mathrm{CC}$ & 2,2 & E & $\mathrm{DE}$ & 0,7 & B & $\mathrm{BB}$ & 1,2 & C & $\mathrm{CC}$ \\
\hline 2011 & 2,3 & $\mathrm{C}$ & $\mathrm{CC}$ & 2,3 & $\mathrm{E}$ & $\mathrm{EE}$ & 0,6 & B & BB & 1,1 & $\mathrm{C}$ & $\mathrm{CC}$ \\
\hline 2012 & 2,2 & C & $\mathrm{CC}$ & 2,4 & E & $\mathrm{EE}$ & 0,6 & B & BB & 1,3 & B & $\mathrm{CB}$ \\
\hline 2013 & 2,1 & D & $\mathrm{CD}$ & 2,5 & $\mathrm{E}$ & $\mathrm{EE}$ & 0,6 & B & BB & 1,5 & A & BA \\
\hline 2014 & 2,1 & D & $\mathrm{DD}$ & 2,4 & E & $\mathrm{EE}$ & 0,7 & B & BB & 1,3 & B & $\mathrm{AB}$ \\
\hline 2015 & 2,0 & D & DD & 2,6 & D & ED & 0,7 & B & $\mathrm{BB}$ & 1,3 & B & $\mathrm{BB}$ \\
\hline
\end{tabular}


Ersin KIRAL

\begin{tabular}{|c|c|c|c|c|c|c|c|c|c|c|c|c|}
\hline \multicolumn{4}{|c|}{ İspanya } & \multicolumn{3}{|c|}{ Fransa } & \multicolumn{3}{|c|}{ Hurvatistan } & \multicolumn{3}{|c|}{ İtalya } \\
\hline Yıl & GO & Kod & Geçiş & GO & Kod & Geçiş & GO & Kod & Geçiş & GO & Kod & Geçiş \\
\hline 1996 & 0,8 & E & & 2,0 & D & & 0,8 & D & & 0,6 & D & \\
\hline 1997 & 0,9 & $\mathrm{E}$ & $\mathrm{EE}$ & 2,0 & D & DD & 0,9 & $\mathrm{D}$ & DD & 0,6 & D & DD \\
\hline 1998 & 0,9 & E & $\mathrm{EE}$ & 2,0 & D & DD & 0,9 & $\mathrm{D}$ & DD & 0,6 & $\mathrm{D}$ & DD \\
\hline 1999 & 0,9 & E & EE & 2,0 & $\mathrm{D}$ & $\mathrm{DD}$ & 0,8 & $\mathrm{D}$ & $\mathrm{DD}$ & 0,7 & $\mathrm{C}$ & $\mathrm{DC}$ \\
\hline 2000 & 0,9 & E & $\mathrm{EE}$ & 1,9 & $\mathrm{D}$ & DD & 1,0 & $\mathrm{C}$ & DC & 0,7 & $\mathrm{C}$ & $\mathrm{CC}$ \\
\hline 2001 & 1,0 & E & $\mathrm{EE}$ & 1,9 & $\mathrm{D}$ & DD & 1,1 & $\mathrm{C}$ & $\mathrm{CC}$ & 0,7 & $\mathrm{C}$ & $\mathrm{CC}$ \\
\hline 2002 & 1,0 & $\mathrm{E}$ & $\mathrm{EE}$ & 1,9 & $\mathrm{D}$ & $\mathrm{DD}$ & 1,0 & $\mathrm{C}$ & $\mathrm{CC}$ & 0,8 & B & $\mathrm{CB}$ \\
\hline 2003 & 1,1 & D & ED & 2,1 & $\mathrm{C}$ & DC & 1,1 & $\mathrm{C}$ & $\mathrm{CC}$ & 0,8 & B & BB \\
\hline 2004 & 1,2 & D & DD & 2,2 & $\mathrm{C}$ & $\mathrm{CC}$ & 1,1 & $\mathrm{C}$ & $\mathrm{CC}$ & 0,8 & B & BB \\
\hline 2005 & 1,7 & B & DB & 2,5 & A & $\mathrm{CA}$ & 1,1 & $\mathrm{C}$ & $\mathrm{CC}$ & 0,8 & B & BB \\
\hline 2006 & 2,1 & A & BA & 2,2 & $\mathrm{C}$ & $\mathrm{AC}$ & 1,1 & $\mathrm{C}$ & $\mathrm{CC}$ & 0,8 & B & $\mathrm{BB}$ \\
\hline 2007 & 2,1 & A & AA & 2,1 & $\mathrm{C}$ & $\mathrm{CC}$ & 1,1 & $\mathrm{C}$ & $\mathrm{CC}$ & 0,8 & B & BB \\
\hline 2010 & 2,2 & A & AA & 2,1 & $\mathrm{C}$ & $\mathrm{CC}$ & 1,2 & B & $\mathrm{CB}$ & 0,9 & A & BA \\
\hline 2011 & 2,2 & A & AA & 2,0 & $\mathrm{D}$ & $\mathrm{CD}$ & 1,3 & B & BB & 0,9 & A & AA \\
\hline 2012 & 2,2 & A & AA & 2,0 & $\mathrm{D}$ & $\mathrm{DD}$ & 1,3 & B & $\mathrm{BB}$ & 0,9 & A & AA \\
\hline 2013 & 2,0 & A & AA & 1,9 & D & DD & 1,4 & A & BA & 0,9 & A & AA \\
\hline 2014 & 2,2 & A & AA & 1,9 & $\mathrm{D}$ & DD & 1,1 & $\mathrm{C}$ & $\mathrm{AC}$ & 0,9 & A & AA \\
\hline 2015 & 2,1 & A & AA & 1,9 & D & DD & 1,4 & A & CA & 1,4 & A & AA \\
\hline \multicolumn{4}{|c|}{ Kıbris } & \multicolumn{3}{|c|}{ Letonya } & \multicolumn{3}{|c|}{ Litvanya } & \multicolumn{3}{|c|}{ Lüksemburg } \\
\hline Yil & GO & Kod & Geçiş & GO & Kod & Geçiş & GO & Kod & Geçiş & GO & Kod & Geçiş \\
\hline 1996 & 1,1 & D & & 2,5 & D & & 3,1 & C & & 2,0 & D & \\
\hline 1997 & 1,3 & D & DD & 2,5 & $\mathrm{D}$ & DD & 3,2 & B & $\mathrm{CB}$ & 2,4 & B & DB \\
\hline 1998 & 1,3 & D & DD & 2,6 & D & DD & 3,3 & B & BB & 2,4 & B & BB \\
\hline 1999 & 1,7 & C & DC & 2,5 & $\mathrm{D}$ & DD & 3,2 & B & BB & 2,4 & B & BB \\
\hline 2000 & 1,7 & C & $\mathrm{CC}$ & 2,6 & D & DD & 3,1 & C & $\mathrm{BC}$ & 2,4 & B & BB \\
\hline 2001 & 1,7 & $\mathrm{C}$ & $\mathrm{CC}$ & 2,4 & E & $\mathrm{DE}$ & 3,2 & B & $\mathrm{CB}$ & 2,3 & $\mathrm{C}$ & $\mathrm{BC}$ \\
\hline 2002 & 1,9 & B & $\mathrm{CB}$ & 2,5 & $\mathrm{D}$ & ED & 3,0 & $\mathrm{C}$ & $\mathrm{BC}$ & 2,4 & B & $\mathrm{CB}$ \\
\hline 2003 & 2,0 & B & BB & 2,1 & $\mathrm{E}$ & $\mathrm{DE}$ & 3,1 & $\mathrm{C}$ & $\mathrm{CC}$ & 2,3 & $\mathrm{C}$ & $\mathrm{BC}$ \\
\hline 2004 & 2,2 & B & $\mathrm{BB}$ & 2,3 & E & $\mathrm{EE}$ & 3,2 & B & $\mathrm{CB}$ & 2,3 & $\mathrm{C}$ & $\mathrm{CC}$ \\
\hline 2005 & 2,0 & B & $\mathrm{BB}$ & 2,8 & D & ED & 3,3 & B & $\mathrm{BB}$ & 2,3 & $\mathrm{C}$ & $\mathrm{CC}$ \\
\hline 2006 & 2,3 & A & BA & 3,2 & $\mathrm{C}$ & $\mathrm{DC}$ & 3,3 & B & BB & 2,5 & B & $\mathrm{CB}$ \\
\hline 2007 & 2,1 & B & $\mathrm{AB}$ & 3,3 & B & $\mathrm{CB}$ & 3,4 & $\mathrm{~A}$ & BA & 2,3 & $\mathrm{C}$ & $\mathrm{BC}$ \\
\hline 2010 & 2,3 & A & BA & 2,4 & $\mathrm{E}$ & $\mathrm{BE}$ & 3,2 & B & $\mathrm{AB}$ & 2,1 & $\mathrm{D}$ & $\mathrm{CD}$ \\
\hline 2011 & 2,3 & A & AA & 4,0 & A & EA & 3,4 & A & BA & 2,3 & $\mathrm{C}$ & DC \\
\hline 2012 & 2,4 & A & AA & 3,6 & B & $\mathrm{AB}$ & 3,5 & A & AA & 2,0 & D & $\mathrm{CD}$ \\
\hline 2013 & 2,2 & B & $\mathrm{AB}$ & 3,5 & B & $\mathrm{BB}$ & 3,4 & A & AA & 2,1 & D & DD \\
\hline 2014 & 2,2 & B & $\mathrm{BB}$ & 3,1 & $\mathrm{C}$ & $\mathrm{BC}$ & 3,3 & $\mathrm{~B}$ & $\mathrm{AB}$ & 2,6 & A & DA \\
\hline 2015 & 2,1 & B & BB & 2,6 & $\mathrm{D}$ & $\mathrm{CD}$ & 3,2 & B & BB & 2,4 & B & $\mathrm{AB}$ \\
\hline \multicolumn{4}{|c|}{ Macaristan } & \multicolumn{3}{|c|}{ Hollanda } & \multicolumn{3}{|c|}{ Avusturya } & \multicolumn{3}{|c|}{ Polonya } \\
\hline Yil & GO & Kod & Geçiş & GO & Kod & Geçiş & GO & Kod & Geçiş & GO & Kod & Geçiş \\
\hline
\end{tabular}


Uluslararası Ekonomi ve Yenilik Dergisi, 4 (1) 2018, 19-38

\begin{tabular}{|c|c|c|c|c|c|c|c|c|c|c|c|c|}
\hline 1996 & 2,2 & B & & 2,2 & B & & 2,3 & B & & 1,0 & $\mathrm{D}$ & \\
\hline 1997 & 2,4 & A & BA & 2,2 & B & BB & 2,3 & B & BB & 1,1 & $\mathrm{D}$ & DD \\
\hline 1998 & 2,5 & A & AA & 2,1 & B & BB & 2,2 & $\mathrm{C}$ & $\mathrm{BC}$ & 1,2 & $\mathrm{D}$ & $\mathrm{DD}$ \\
\hline 1999 & 2,5 & A & AA & 2,1 & B & BB & 2,3 & B & $\mathrm{CB}$ & 1,1 & $\mathrm{D}$ & DD \\
\hline 2000 & 2,3 & B & $\mathrm{AB}$ & 2,2 & B & BB & 2,4 & B & BB & 1,1 & $\mathrm{D}$ & DD \\
\hline 2001 & 2,4 & A & BA & 2,3 & A & BA & 2,6 & $\mathrm{~A}$ & BA & 1,2 & $\mathrm{D}$ & $\mathrm{DD}$ \\
\hline 2002 & 2,5 & A & AA & 2,1 & B & $\mathrm{AB}$ & 2,4 & B & $\mathrm{AB}$ & 1,2 & D & $\mathrm{DD}$ \\
\hline 2003 & 2,5 & A & AA & 1,9 & $\mathrm{C}$ & $\mathrm{BC}$ & 2,3 & B & BB & 1,3 & C & DC \\
\hline 2004 & 2,4 & A & $\mathrm{AA}$ & 1,9 & $\mathrm{C}$ & $\mathrm{CC}$ & 2,4 & B & BB & 1,5 & $\mathrm{C}$ & $\mathrm{CC}$ \\
\hline 2005 & 2,5 & A & AA & 2,0 & $\mathrm{C}$ & $\mathrm{CC}$ & 2,4 & B & BB & 1,8 & B & $\mathrm{CB}$ \\
\hline 2006 & 2,5 & A & $\mathrm{AA}$ & 1,9 & $\mathrm{C}$ & $\mathrm{CC}$ & 2,5 & A & BA & 1,9 & A & $\mathrm{BA}$ \\
\hline 2007 & 2,5 & A & AA & 2,0 & $\mathrm{C}$ & $\mathrm{CC}$ & 2,4 & B & $\mathrm{AB}$ & 1,7 & B & $\mathrm{AB}$ \\
\hline 2010 & 2,4 & A & $\mathrm{AA}$ & 2,0 & C & $\mathrm{CC}$ & 2,1 & C & BC & 1,6 & B & BB \\
\hline 2011 & 2,3 & B & $\mathrm{AB}$ & 2,0 & $\mathrm{C}$ & $\mathrm{CC}$ & 2,1 & $\mathrm{C}$ & $\mathrm{CC}$ & 1,7 & B & $\mathrm{BB}$ \\
\hline 2012 & 2,2 & B & BB & 2,1 & B & $\mathrm{CB}$ & 2,0 & D & $\mathrm{CD}$ & 1,7 & B & BB \\
\hline 2013 & 2,0 & $\mathrm{C}$ & $\mathrm{BC}$ & 2,0 & $\mathrm{C}$ & $\mathrm{BC}$ & 1,9 & $\mathrm{D}$ & $\mathrm{DD}$ & 1,7 & B & BB \\
\hline 2014 & 2,0 & C & $\mathrm{CC}$ & 2,1 & B & $\mathrm{CB}$ & 1,9 & D & $\mathrm{DD}$ & 1,7 & B & $\mathrm{BB}$ \\
\hline 2015 & 2,1 & $\mathrm{C}$ & $\mathrm{CC}$ & 2,0 & $\mathrm{C}$ & $\mathrm{BC}$ & 1,9 & D & $\mathrm{DD}$ & 1,8 & $B$ & $\mathrm{BB}$ \\
\hline \multicolumn{4}{|c|}{ Portekiz } & \multicolumn{3}{|c|}{ Romanya } & \multicolumn{3}{|c|}{ Slovenya } & \multicolumn{3}{|c|}{ Slovakya } \\
\hline Yıl & GO & Kod & Geçiş & GO & Kod & Geçiş & GO & Kod & Geçiş & GO & Kod & Geçiş \\
\hline 1996 & 1,3 & $\mathrm{E}$ & & 1,6 & B & & 1,0 & $\mathrm{C}$ & & 1,7 & $\mathrm{D}$ & \\
\hline 1997 & 1,4 & E & $\mathrm{EE}$ & 1,6 & B & BB & 1,0 & $\mathrm{C}$ & $\mathrm{CC}$ & 1,7 & $\mathrm{D}$ & DD \\
\hline 1998 & 1,5 & $\mathrm{E}$ & $\mathrm{EE}$ & 1,6 & B & BB & 1,0 & $\mathrm{C}$ & $\mathrm{CC}$ & 1,7 & $\mathrm{D}$ & $\mathrm{DD}$ \\
\hline 1999 & 1,7 & $\mathrm{D}$ & ED & 1,6 & B & $\mathrm{BB}$ & 1,0 & $\mathrm{C}$ & $\mathrm{CC}$ & 1,8 & $\mathrm{D}$ & DD \\
\hline 2000 & 1,9 & $\mathrm{C}$ & DC & 1,4 & $\mathrm{C}$ & $\mathrm{BC}$ & 1,1 & $\mathrm{C}$ & $\mathrm{CC}$ & 1,7 & D & DD \\
\hline 2001 & 1,8 & $\mathrm{D}$ & $\mathrm{CD}$ & 1,4 & $\mathrm{C}$ & $\mathrm{CC}$ & 1,1 & $\mathrm{C}$ & $\mathrm{CC}$ & 1,8 & D & DD \\
\hline 2002 & 2,7 & A & DA & 1,5 & $\mathrm{C}$ & $\mathrm{CC}$ & 1,2 & B & $\mathrm{CB}$ & 2,0 & $\mathrm{C}$ & $\mathrm{DC}$ \\
\hline 2003 & 2,2 & B & $\mathrm{AB}$ & 1,5 & $\mathrm{C}$ & $\mathrm{CC}$ & 1,2 & B & $\mathrm{BC}$ & 2,0 & $\mathrm{C}$ & $\mathrm{CC}$ \\
\hline 2004 & 2,2 & $\mathrm{~B}$ & $\mathrm{BB}$ & 1,6 & $\mathrm{~B}$ & $\mathrm{CB}$ & 1,2 & B & $\mathrm{BB}$ & 2,0 & $\mathrm{C}$ & $\mathrm{CC}$ \\
\hline 2005 & 2,2 & B & $\mathrm{BB}$ & 1,5 & $\mathrm{C}$ & $\mathrm{BC}$ & 1,3 & B & $\mathrm{BB}$ & 2,1 & B & $\mathrm{CB}$ \\
\hline 2006 & 2,3 & B & $\mathrm{BB}$ & 1,5 & $\mathrm{C}$ & $\mathrm{CC}$ & 1,2 & B & $\mathrm{BB}$ & 2,4 & A & $\mathrm{BA}$ \\
\hline 2007 & 2,4 & B & $\mathrm{BB}$ & 1,7 & B & $\mathrm{CB}$ & 1,4 & A & $\mathrm{BA}$ & 2,3 & A & $\mathrm{AA}$ \\
\hline 2010 & 2,6 & $\mathrm{~A}$ & $\mathrm{BA}$ & 1,6 & $\mathrm{~B}$ & $\mathrm{BB}$ & 1,2 & B & $\mathrm{AB}$ & 2,2 & B & $\mathrm{AB}$ \\
\hline 2011 & 2,5 & A & AA & 1,8 & A & BA & 1,1 & $\mathrm{C}$ & $\mathrm{BC}$ & 2,1 & B & BB \\
\hline 2012 & 2,4 & B & $\mathrm{AB}$ & 1,6 & B & $\mathrm{AB}$ & 1,2 & B & $\mathrm{CB}$ & 2,0 & $\mathrm{C}$ & $\mathrm{BC}$ \\
\hline 2013 & 2,2 & B & $\mathrm{BB}$ & 1,4 & $\mathrm{C}$ & $\mathrm{BC}$ & 1,1 & $\mathrm{C}$ & $\mathrm{BC}$ & 2,0 & $\mathrm{C}$ & $\mathrm{CC}$ \\
\hline 2014 & 2,4 & $\mathrm{~B}$ & $\mathrm{BB}$ & 1,4 & $\mathrm{C}$ & $\mathrm{CC}$ & 1,2 & $\mathrm{~B}$ & $\mathrm{CB}$ & 1,9 & $\mathrm{C}$ & $\mathrm{CC}$ \\
\hline 2015 & 2,4 & B & $\mathrm{BB}$ & 1,6 & B & $\mathrm{CB}$ & 1,2 & B & $\mathrm{BB}$ & 1,8 & $\mathrm{D}$ & $\mathrm{CD}$ \\
\hline \multicolumn{4}{|c|}{ Finlandiya } & \multicolumn{3}{|c|}{ İsveç } & \multicolumn{3}{|c|}{ İngiltere } & \multicolumn{3}{|c|}{ Türkiye } \\
\hline Yll & GO & Kod & Geçiş & GO & Kod & Geçiş & GO & Kod & Geçiş & GO & Kod & $\begin{array}{c}\text { Geçişle } \\
\text { r }\end{array}$ \\
\hline 1996 & 2,7 & A & & 2,4 & $\mathrm{C}$ & & 3,0 & A & & 1,37 & $\mathrm{D}$ & \\
\hline 1997 & 2,6 & A & AA & 2,4 & $\mathrm{C}$ & $\mathrm{CC}$ & 2,8 & A & AA & 1,37 & $\mathrm{D}$ & DD \\
\hline
\end{tabular}


Ersin KIRAL

\begin{tabular}{llll|lll|lll|lll}
\hline 1998 & 2,7 & A & AA & 2,3 & D & CD & 2,7 & B & AB & 1,37 & D & DD \\
\hline 1999 & 2,7 & A & AA & 2,4 & C & DC & 2,7 & B & BB & 1,37 & D & DD \\
\hline 2000 & 2,7 & A & AA & 2,4 & C & CC & 2,6 & B & BB & 1,37 & D & DD \\
\hline 2001 & 2,6 & A & AA & 2,4 & C & CC & 2,7 & B & BB & 1,41 & D & DD \\
\hline 2002 & 2,6 & A & AA & 2,4 & C & CC & 2,7 & B & BB & 1,44 & D & DD \\
\hline 2003 & 2,6 & A & AA & 2,4 & C & CC & 2,8 & A & BA & 1,39 & D & DD \\
\hline 2004 & 2,5 & B & AB & 2,2 & D & CD & 2,8 & A & AA & 1,35 & D & DD \\
\hline 2005 & 2,6 & A & BA & 2,2 & D & DD & 2,6 & B & AB & 1,40 & D & DD \\
\hline 2006 & 2,5 & B & AB & 2,2 & D & DD & 2,5 & B & BB & 1,35 & D & DD \\
\hline 2007 & 2,5 & B & BB & 2,3 & D & DD & 2,5 & B & BB & 1,34 & D & DD \\
\hline 2010 & 2,5 & B & BB & 2,5 & C & DC & 2,1 & D & BD & 1,62 & B & DB \\
\hline 2011 & 2,5 & B & BB & 2,5 & C & CC & 2,1 & D & DD & 1,62 & B & BB \\
\hline 2012 & 2,4 & B & BB & 2,5 & C & CC & 2,0 & D & DD & 1,64 & B & BB \\
\hline 2013 & 2,5 & B & BB & 2,8 & A & CA & 2,0 & D & DD & 1,65 & A & BA \\
\hline 2014 & 2,5 & B & BB & 2,7 & B & AB & 1,9 & D & DD & 1,70 & A & AA \\
\hline 2015 & 2,5 & B & BB & 2,5 & C & BC & 2,5 & B & DB & 1,69 & A & AA \\
\hline
\end{tabular}

Tablo A2. Boşanma Oranları Olasılık Geçiş Matrisleri

\begin{tabular}{|c|c|c|c|c|c|c|c|c|c|c|c|c|c|}
\hline \multicolumn{7}{|c|}{ Belçika } & \multicolumn{7}{|c|}{ Estonya } \\
\hline \multicolumn{2}{|l|}{$\mathrm{BH}(\%)$} & $\mathrm{A}$ & B & \multirow{2}{*}{$\begin{array}{l}\mathrm{C} \\
0\end{array}$} & \multirow{2}{*}{$\begin{array}{l}\mathrm{D} \\
0\end{array}$} & \multirow{2}{*}{$\begin{array}{c}\mathrm{E} \\
0\end{array}$} & \multicolumn{2}{|l|}{$\mathrm{BH}(\%)$} & A & \multirow{2}{*}{$\begin{array}{l}\mathrm{B} \\
0\end{array}$} & \multirow{2}{*}{$\frac{C}{1 / 3}$} & \multirow{2}{*}{$\begin{array}{l}\mathrm{D} \\
0\end{array}$} & \multirow{2}{*}{$\begin{array}{l}\mathrm{E} \\
0\end{array}$} \\
\hline $3,0 \leq r \leq$ & A & $2 / 3$ & $1 / 3$ & & & & $3,8 \leq r \leq$ & A & $2 / 3$ & & & & \\
\hline $2,8 \leq r \leq$ & B & $1 / 5$ & $2 / 5$ & $2 / 5$ & 0 & 0 & $3,4 \leq r \leq$ & B & 0 & 0 & 0 & 0 & 0 \\
\hline $2,6 \leq r \leq$ & $\mathrm{C}$ & 0 & $1 / 5$ & $3 / 5$ & $1 / 5$ & 0 & $3,0 \leq r \leq$ & $\mathrm{C}$ & $1 / 6$ & 0 & $3 / 6$ & $2 / 6$ & 0 \\
\hline $2,7 \leq r \leq$ & $\mathrm{D}$ & 0 & 0 & 0 & 0 & 1 & $2^{2}, 6^{2} \leq r \leq$ & $\mathrm{D}$ & 0 & 0 & $1 / 3$ & $1 / 3$ & $1 / 3$ \\
\hline $\begin{array}{l}3,2 \leq x \leq \\
2,2\end{array}$ & $\mathrm{E}$ & 0 & 0 & 0 & 0 & 1 & $\begin{array}{l}3,2 \leq \\
2,2 \leq r \leq \\
25\end{array}$ & $\mathrm{E}$ & 0 & 0 & 0 & $1 / 5$ & $4 / 5$ \\
\hline \multicolumn{7}{|c|}{ İrlanda } & \multicolumn{7}{|c|}{ Yunanistan } \\
\hline $\mathrm{GO}(\%)$ & & A & B & $\mathrm{C}$ & $\mathrm{D}$ & E & $\mathrm{GO}(\%)$ & & A & B & $\mathrm{C}$ & $\mathrm{D}$ & E \\
\hline $0,8 \leq r \leq$ & A & $1 / 2$ & $1 / 2$ & 0 & 0 & 0 & $1,5 \leq r \leq$ & $\mathrm{A}$ & 0 & 1 & 0 & 0 & 0 \\
\hline$\hat{0}, \hat{6} \leq r \leq$ & B & $1 / 12$ & $11 / 12$ & 0 & 0 & 0 & $1,3 \leq r \leq$ & B & $1 / 3$ & $1 / 3$ & $1 / 3$ & 0 & 0 \\
\hline $\begin{array}{l}\hat{n} 7 \\
0,4 \leq r \leq \\
n \leq\end{array}$ & $\mathrm{C}$ & 0 & 1 & 0 & 0 & 0 & $\hat{1}, \hat{1} \leq r \leq$ & $\mathrm{C}$ & 0 & $2 / 7$ & $4 / 7$ & $1 / 7$ & 0 \\
\hline $\begin{array}{l}0,2 \leq r \leq \\
n_{2}\end{array}$ & $\mathrm{D}$ & 0 & 0 & 0 & 0 & 0 & $0,9 \leq r \leq$ & D & 0 & 0 & $2 / 5$ & $2 / 5$ & $1 / 5$ \\
\hline $\begin{array}{l}0,0 \leq r \leq \\
0.1\end{array}$ & $\mathrm{E}$ & 0 & 0 & $1 / 2$ & 0 & $1 / 2$ & $\begin{array}{l}0,7 \leq r \leq \\
\mathrm{Q} \mathrm{Q}\end{array}$ & $\mathrm{E}$ & 0 & 0 & 0 & 1 & 0 \\
\hline \multicolumn{7}{|c|}{ Letonya } & \multicolumn{7}{|c|}{ Portekiz } \\
\hline $\mathrm{GO}(\%)$ & & A & B & $\mathrm{C}$ & $\mathrm{D}$ & $\mathrm{E}$ & $\mathrm{GO}(\%)$ & & A & $\mathrm{B}$ & $\mathrm{C}$ & $\mathrm{D}$ & $\mathrm{E}$ \\
\hline $3,7 \leq r \leq$ & A & 0 & 1 & 0 & 0 & 0 & $2,5 \leq r \leq$ & A & $1 / 3$ & $2 / 3$ & 0 & 0 & 0 \\
\hline $3,3 \leq r \leq$ & B & 0 & $1 / 3$ & $1 / 3$ & 0 & $1 / 3$ & $2,2 \leq r \leq$ & B & $1 / 8$ & $7 / 8$ & 0 & 0 & 0 \\
\hline $2,9 \leq r \leq$ & $\mathrm{C}$ & 0 & $1 / 2$ & 0 & $1 / 2$ & 0 & $1,9 \leq r \leq$ & $\mathrm{C}$ & 0 & 0 & 0 & 1 & 0 \\
\hline $2,5 \leq r \leq$ & $\mathrm{D}$ & 0 & 0 & $1 / 7$ & $4 / 7$ & $2 / 7$ & $\begin{array}{l}1,6 \leq r \leq \\
18\end{array}$ & $\mathrm{D}$ & $1 / 2$ & 0 & $1 / 2$ & 0 & 0 \\
\hline $\begin{array}{l}2,1 \leq r \leq \\
2,\end{array}$ & $\mathrm{E}$ & $1 / 4$ & 0 & 0 & $2 / 4$ & $1 / 4$ & $\begin{array}{l}1,3 \leq r \leq \\
1,5\end{array}$ & $\mathrm{E}$ & 0 & 0 & 0 & $1 / 3$ & $2 / 3$ \\
\hline \multicolumn{7}{|c|}{ Bulgaristan } & \multicolumn{7}{|c|}{ Çek Cumhuriyeti } \\
\hline $\mathrm{GO}(\%)$ & & & & & $\mathrm{C}$ & $\mathrm{D}$ & $\mathrm{GO}(\%)$ & & & & B & $\mathrm{C}$ & $\mathrm{D}$ \\
\hline $\begin{array}{l}2,0 \leq r \leq \\
\text { ? }\end{array}$ & 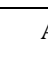 & & & & 1 & 0 & $\begin{array}{l}3,5 \leq r \leq \\
20\end{array}$ & & & & 1 & 0 & 0 \\
\hline
\end{tabular}


Uluslararası Ekonomi ve Yenilik Dergisi, 4 (1) 2018, 19-38

\begin{tabular}{|c|c|c|c|c|c|c|c|c|c|c|c|}
\hline $1,7 \leq r \leq$ & B & $1 / 3$ & $2 / 3$ & 0 & 0 & $3,1 \leq r \leq$ & B & $1 / 8$ & $5 / 8$ & $1 / 8$ & $1 / 8$ \\
\hline $1,4 \leq r \leq$ & $\mathrm{C}$ & 0 & $1 / 6$ & $5 / 6$ & 0 & $2,7 \leq r \leq$ & $\mathrm{C}$ & 0 & $1 / 5$ & $2 / 5$ & $2 / 5$ \\
\hline $\begin{array}{l}1,6 \\
1,1 \leq r \leq\end{array}$ & $\mathrm{D}$ & 0 & 0 & $1 / 7$ & $6 / 7$ & $\begin{array}{l}2,3 \\
2,3 \leq r \leq \\
26\end{array}$ & $\mathrm{D}$ & 0 & 0 & $2 / 3$ & $1 / 3$ \\
\hline \multicolumn{6}{|c|}{ Danimarka } & \multicolumn{6}{|c|}{ Almanya } \\
\hline $\mathrm{GO}(\%)$ & & A & $\mathrm{B}$ & $\mathrm{C}$ & $\mathrm{D}$ & $\mathrm{GO}(\%)$ & & A & B & $\mathrm{C}$ & $\mathrm{D}$ \\
\hline $3,3 \leq r \leq$ & A & 0,5 & 0 & 0,5 & 0 & $2,6 \leq r \leq 2,7$ & A & 0,5 & 0,5 & 0 & 0 \\
\hline $3,0 \leq r \leq$ & B & 0 & 0 & 0 & 0 & $2,4 \leq r \leq 2,5$ & B & $1 / 4$ & $2 / 4$ & $1 / 4$ & 0 \\
\hline $2, \overline{7} \leq r \leq$ & $\mathrm{C}$ & $1 / 7$ & 0 & $5 / 7$ & $1 / 7$ & $2,2 \leq r \leq 2,3$ & $\mathrm{C}$ & 0 & $1 / 8$ & $6 / 8$ & $1 / 8$ \\
\hline $\begin{array}{l}2,0 \\
2,4 \leq r \leq \\
26\end{array}$ & $\mathrm{D}$ & 0 & 0 & $2 / 8$ & $6 / 8$ & $2,0 \leq r \leq 2,1$ & $\mathrm{D}$ & 0 & 0 & $1 / 3$ & $2 / 3$ \\
\hline \multicolumn{6}{|c|}{ Fransa } & \multicolumn{6}{|c|}{ Hirvatistan } \\
\hline $\mathrm{GO}(\%)$ & & A & $\mathrm{B}$ & $\mathrm{C}$ & $\mathrm{D}$ & $\mathrm{GO}(\%)$ & & A & $\mathrm{B}$ & $\mathrm{C}$ & $\mathrm{D}$ \\
\hline $2,5 \leq r \leq$ & A & 0 & 0 & 1 & 0 & $1,4 \leq r \leq 1,5$ & A & 0 & 0 & 1 & 0 \\
\hline $2, \hat{3} \leq r \leq$ & B & 0 & 0 & 0 & 0 & $1,2 \leq r \leq 1,3$ & B & $1 / 3$ & $2 / 3$ & 0 & 0 \\
\hline$\hat{2} \hat{1} \leq r \leq$ & $\mathrm{C}$ & $1 / 5$ & 0 & $3 / 5$ & $1 / 5$ & $1,0 \leq r \leq 1,1$ & $\mathrm{C}$ & $1 / 9$ & $1 / 9$ & $7 / 9$ & 0 \\
\hline$\hat{1}, \hat{9} \leq r \leq$ & $\mathrm{D}$ & 0 & 0 & $1 / 11$ & $10 / 11$ & $0,8 \leq r \leq 0,9$ & $\mathrm{D}$ & 0 & 0 & $1 / 4$ & $3 / 4$ \\
\hline \multicolumn{6}{|c|}{ İtalya } & \multicolumn{6}{|c|}{ Kıbris Rum Kesimi } \\
\hline $\mathrm{GO}(\%)$ & & A & B & $\mathrm{C}$ & $\mathrm{D}$ & $\mathrm{GO}(\%)$ & & A & B & $\mathrm{C}$ & $\mathrm{D}$ \\
\hline $0,9 \leq r<$ & A & 1 & 0 & 0 & 0 & $2,3 \leq r \leq 2,6$ & A & $1 / 2$ & $1 / 2$ & 0 & 0 \\
\hline $\begin{array}{l}0,8 \leq r< \\
n \text { o }\end{array}$ & $\mathrm{B}$ & $1 / 6$ & $5 / 6$ & 0 & 0 & $1,9 \leq r \leq 2,2$ & B & $2 / 7$ & $5 / 7$ & 0 & 0 \\
\hline $\begin{array}{l}0,7 \leq r< \\
n \in \mathbb{Q}\end{array}$ & $\mathrm{C}$ & 0 & $1 / 3$ & $2 / 3$ & 0 & $1,5 \leq r \leq 1,8$ & $\mathrm{C}$ & 0 & $1 / 3$ & $2 / 3$ & 0 \\
\hline $0,6 \leq r<$ & $\mathrm{D}$ & 0 & 0 & $1 / 3$ & $2 / 3$ & $1,1 \leq r \leq 1,4$ & $\mathrm{D}$ & 0 & 0 & $1 / 3$ & $2 / 3$ \\
\hline \multicolumn{6}{|c|}{ Lüksemburg } & \multicolumn{6}{|c|}{ Avusturya } \\
\hline $\mathrm{GO}(\%)$ & & A & B & $\mathrm{C}$ & $\mathrm{D}$ & $\mathrm{GO}(\%)$ & & A & B & $\mathrm{C}$ & $\mathrm{D}$ \\
\hline $2,6 \leq r \leq$ & A & 0 & 1 & 0 & 0 & $2,5 \leq r \leq 2,6$ & A & 0 & 1 & 0 & 0 \\
\hline $2,4 \leq r \leq$ & B & 0 & $1 / 2$ & $1 / 2$ & 0 & $2,3 \leq r \leq 2,4$ & $\mathrm{~B}$ & $2 / 9$ & $5 / 9$ & $2 / 9$ & 0 \\
\hline $2,1 \leq r \leq$ & $\mathrm{C}$ & 0 & $2 / 6$ & $2 / 6$ & $2 / 6$ & $2,1 \leq r \leq 2,2$ & $\mathrm{C}$ & 0 & $1 / 3$ & $1 / 3$ & $1 / 3$ \\
\hline $2,0 \leq r \leq$ & $\mathrm{D}$ & $1 / 3$ & 0 & $1 / 3$ & $1 / 3$ & $1,9 \leq r \leq 2,0$ & $\mathrm{D}$ & 0 & 0 & 0 & 1 \\
\hline \multicolumn{6}{|c|}{ Polonya } & \multicolumn{6}{|c|}{ Slovakya } \\
\hline $\mathrm{GO}(\%)$ & & A & $\mathrm{B}$ & $\mathrm{C}$ & $\mathrm{D}$ & $\mathrm{GO}(\%)$ & & A & B & $\mathrm{C}$ & \\
\hline $1,9 \leq r \leq$ & A & 0 & 1 & 0 & 0 & $2,3 \leq r \leq 2,5$ & A & $1 / 2$ & $1 / 2$ & 0 & \\
\hline $\begin{array}{l}\hat{1}, 6 \leq \\
10\end{array}$ & B & $1 / 7$ & $6 / 7$ & 0 & 0 & $2,0 \leq r \leq 2,2$ & $\mathrm{~B}$ & $1 / 5$ & $3 / 5$ & $1 / 5$ & \\
\hline $\begin{array}{l}1,3 \leq r \leq \\
15\end{array}$ & $\mathrm{C}$ & 0 & $1 / 2$ & $1 / 2$ & 0 & $1,7 \leq r \leq 1,9$ & $\mathrm{C}$ & 0 & $1 / 7$ & $6 / 7$ & \\
\hline $1,0 \leq r \leq$ & $\mathrm{D}$ & 0 & 0 & $1 / 7$ & $6 / 7$ & & & & & & \\
\hline \multicolumn{6}{|c|}{ İsveç } & \multicolumn{6}{|c|}{ İngiltere } \\
\hline $\mathrm{GO}(\%)$ & & A & B & $\mathrm{C}$ & $\mathrm{D}$ & $\mathrm{GO}(\%)$ & & A & $\mathrm{B}$ & $\mathrm{C}$ & $\mathrm{D}$ \\
\hline $2,8 \leq r \leq$ & A & 0 & 1 & 0 & 0 & $2,8 \leq r \leq 3,0$ & A & 0,5 & 0,5 & 0 & 0 \\
\hline $2,6 \leq r \leq$ & B & 0 & 0 & 1 & 0 & $2,5 \leq r \leq 2,7$ & B & $1 / 8$ & $6 / 8$ & 0 & $1 / 8$ \\
\hline $2,7 \leq r \leq$ & $\mathrm{C}$ & $1 / 10$ & 0 & $7 / 10$ & $2 / 10$ & $2,2 \leq r \leq 2,4$ & $\mathrm{C}$ & 0 & 0 & 0 & 0 \\
\hline $2,2 \leq r \leq$ & $\mathrm{D}$ & 0 & 0 & $2 / 5$ & $3 / 5$ & $1,9 \leq r \leq 2,1$ & $\mathrm{D}$ & 0 & $1 / 5$ & 0 & $4 / 5$ \\
\hline \multicolumn{6}{|c|}{ İspanya } & \multicolumn{6}{|c|}{ Türkiye } \\
\hline $\mathrm{GO}(\%)$ & & A & $\mathrm{B}$ & $\mathrm{D}$ & $\mathrm{E}$ & $\mathrm{GO}(\%)$ & & A & $\mathrm{B}$ & $\mathrm{C}$ & $\mathrm{D}$ \\
\hline $2,0 \leq r \leq$ & A & 1 & 0 & 0 & 0 & $1,65 \leq r \leq 1,74$ & A & 1 & 0 & 0 & 0 \\
\hline$\hat{1}, \hat{7} \leq r \leq$ & B & 0 & 1 & 0 & 0 & $1,55 \leq r \leq 1,64$ & B & $1 / 3$ & $2 / 3$ & 0 & 0 \\
\hline $1, \hat{4} \leq r \leq$ & $\mathrm{C}$ & 0 & 0 & 0 & 0 & $1,45 \leq r \leq 1,54$ & $\mathrm{C}$ & 0 & 0 & 0 & 0 \\
\hline
\end{tabular}


Ersin KIRAL

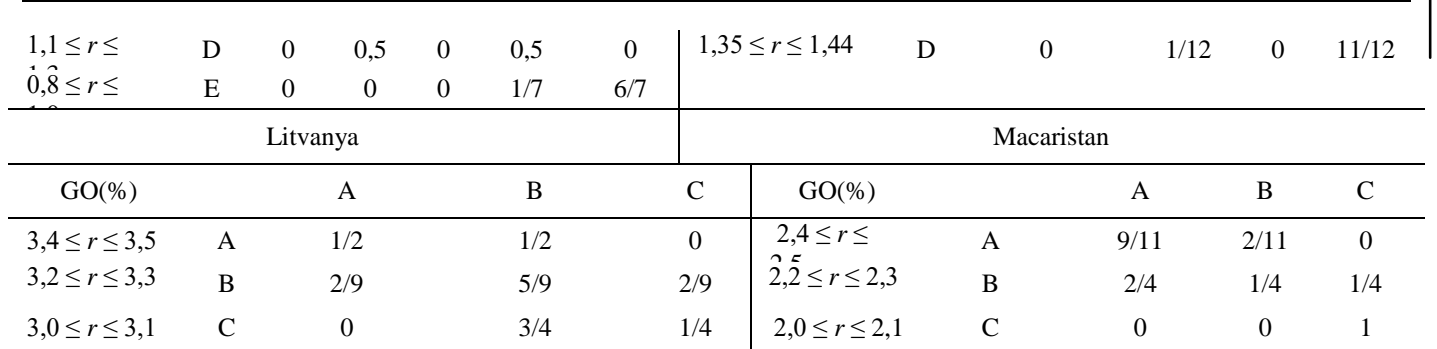

